\title{
Trends of Rainfall in Sri Lanka over the Last Century
}

\author{
H.K.W.I. Jayawardene ${ }^{1}$, D.U.J. Sonnadara ${ }^{1, *}$ and D.R. Jayewardene ${ }^{2}$ \\ ${ }^{1}$ Department of Physics, University of Colombo, Colombo 00300, Sri Lanka, \\ ${ }^{2}$ Department of Mathematics, University of Colombo, Colombo 00300, Sri Lanka
}

\begin{abstract}
Utilizing over 100 years of rainfall records in 15 meteorology stations, an analysis was carried out to extract the trends of annual rainfall depth in Sri Lanka over the last century. A statistically significant increasing trend of rate $3.15 \mathrm{~mm} /$ year was observed at Colombo and decreasing trends were observed at Nuwara Eliya and Kandy with rates of $4.87 \mathrm{~mm} /$ year and $2.88 \mathrm{~mm} / \mathrm{year}$ respectively. Since no coherent increase or decrease of rainfall in any group of stations in the wet or dry zones was observed, the possibility of large scale change over the past century was ruled out. However, more recent data records (1949 onwards), revealed a decreasing trends in 13 of the 15 stations. Thus, traces of a temporal change seem to be apparent in the rainfall records over the last half century. In general, the downward trends in recent decades are steeper than the long term variations. For the recent data records, the largest downward trend of $11.16 \mathrm{~mm} / \mathrm{year}$ was observed at Batticaloa.
\end{abstract}

\section{INTRODUCTION}

Sri Lanka's economy depends heavily on the availability of water resources. Rain-fed and irrigated agriculture contributes to $22 \%$ of Sri Lankan exports while the industries that contribute to $75 \%$ of exports use electricity from the national grid of which $62 \%$ is generated through hydropower. The amount of water consumption has also increased in the past decades 
due to the increase in population and developments in irrigation and agricultural and industrial processes. Even though Sri Lanka has a high average rainfall due to its tropical and monsoonal climate, highly seasonal and spatial variability of rainfall creates periodic shortages of water for both agricultural and domestic use.

Detailed knowledge of variations in rainfall is essential for proper water management practices. Thus, understanding the variations in rainfall both spatially and temporally and improving the ability of forecasting rainfall may help in planning crop cultivation as well as in designing water storages, planning drainage channels for flood mitigation etc.

The work discussed in this paper focuses on extracting the trends and seasonal patterns of rainfall on a set of selected weather stations by utilizing statistical techniques. The work was carried out with monthly and annual rainfall data recorded on 15 stations within a time span of 98 to 130 years. Emphasis is given to find out whether there is any significant change in the rainfall time series records over the years.

\section{DATA}

Rainfall over Sri Lanka is governed by its tropical location as well as by the monsoonal regime and thus has a strong seasonal variation in the rainfall pattern. Furthermore, the northward and southward migrations of the Inter Tropical Convergence Zone (ITCZ) during the year also govern the climate. Four seasons were identified in past studies [1]. These are the Northeast monsoon from December to February, South-West monsoon from May to September, First intermonsoon from March to April and Second intermonsoon from October to November. A total of 15 weather stations were selected to capture the diverse seasonal variation across the land mass, which is essential for this analysis.

Although Sri Lanka has a very good network of weather observatories with rainfall records extending over a century, some data records consist of a considerable percentage of missing values. The bulk of the data for this work were extracted from monthly rainfall and temperature figures for the period 1869-1980 published by Yoshino and Suppiah based on the

\footnotetext{
*Corresponding Author, E-mail: upul@phys.cmb.ac.lk
} 
data records maintained by the Department of Meteorology, Sri Lanka [2]. They have applied the necessary quality control checks on the data and estimated missing values using difference and ratio methods suggested by Thom [3]. The recent data records were obtained from the IRI monthly climatic data (IRI/LDEO Climate data Library) and Statistical abstracts from the Department of Meteorology as well as through direct purchase. Table 1 shows a summary of the selected rainfall stations used in this work.

Table 1: Summary of rainfall data used in this study. Here elevation represents height of the rain gauge position from sea level

\begin{tabular}{lcrrr}
\hline \multicolumn{1}{c}{ Station Name } & Period & Latitude $\left({ }^{\circ} \mathrm{N}\right)$ & Longitude $\left({ }^{\circ} \mathrm{E}\right)$ & Elevation $(\mathrm{m})$ \\
\hline Colombo & $1869-1998$ & 6.90 & 79.87 & 7 \\
Nuwara Eliya & $1869-1998$ & 6.96 & 80.77 & 1895 \\
Rathnapura & $1869-1998$ & 6.68 & 80.40 & 34 \\
Kandy & $1870-1998$ & 7.33 & 80.63 & 478 \\
Anuradhapura & $1870-1998$ & 8.35 & 80.38 & 93 \\
Diyatalawa & $1901-1998$ & 6.82 & 80.97 & 1248 \\
Galle & $1869-1993$ & 6.03 & 80.22 & 13 \\
Badulla & $1869-1993$ & 6.98 & 81.03 & 670 \\
Puttalam & $1869-1993$ & 8.03 & 79.83 & 2 \\
Batticaloa & $1869-1993$ & 7.72 & 81.70 & 3 \\
Kurunegala & $1885-1993$ & 7.47 & 80.37 & 116 \\
Trincomalee & $1869-1986$ & 8.58 & 81.25 & 3 \\
Mannar & $1870-1985$ & 8.97 & 79.90 & 4 \\
Jaffna & $1871-1984$ & 9.65 & 80.02 & 4 \\
Hambantota & $1869-1987$ & 6.12 & 81.12 & 16 \\
\hline
\end{tabular}

\section{METHODOLOGY}

Among many statistical tests available to detect trend in a time series, the Mann-Kendall rank statistic, the Spearman rank statistic and the least-square regression method were chosen for the present work. The Mann-Kendall rank statistic is a non-parametric test, which can be used to test for the existence of a linear trend while the Spearman's test confirms the result [4]. 
The Mann-Kendall rank statistic $t_{m}$ is computed, by first replacing the observations $x_{i}$ 's by their ranks $k_{i}$ 's such that each term is assigned a number ranging from 1 to $n$ which reflects its magnitude relative to the magnitudes of all other terms. For each element $k_{i}$, the number $N_{i}$ is calculated as the number of $k_{j}$ terms preceding it such that $k_{j}>k_{i}$. Then $t_{m}$ is given by,

$$
t_{m}=\frac{4 \sum_{i}^{n-1} N_{i}}{n(n-1)}-1
$$

$t_{m}$ is distributed very nearly as a normal distribution for large $n$ and can be used as the basis of a significance test,

$$
r_{m}= \pm r_{g} \sqrt{\frac{4 n+10}{9 n(n-1)}}
$$

where $r_{g}$ is the desired probability point of the normal distribution appropriate to a two-tailed test. If $t_{m}$ lies inside the range $\pm r_{m}$ then the time series does not contain a trend.

The calculation of the Spearman rank statistic $r_{s}$ requires that the original observations $x_{I}$ 's are transformed to ranks $k_{i}$ 's by arranging them in increasing order of magnitude. Then by computing the quantity $d_{i}$ as $d_{i}=k_{i}-i$, where $i$ ranges from 1 to $n, r_{s}$ is defined by the equation,

$$
r_{s}=1-\frac{6 \sum_{i=1}^{n} d_{i}^{2}}{n\left(n^{2}-1\right)}
$$

For large $n$, the value of $r_{s}$ can be tested for significance by calculating the quantity $t_{s}$ given by the equation 


$$
t_{s}=r_{s} \sqrt{\frac{n-2}{1-r_{s}^{2}}}
$$

If the computed $t_{s}$ lie within the desired confidence limits of the two-tailed test, we can conclude that there is no trend in the data series.

\section{RESULTS AND DISCUSSION}

To test the existence of a linear trend, the data set was divided into two time periods and analyzed. The results of these tests are summarized in table 2 (98 to 130 years) and table 3 (36 to 50 years) respectively. Table 3 was especially generated with recent data records to test whether there is any change in rainfall patterns due to global climate change caused by the rapid industrial expansions in the West that arose after the 1940s [5].

For the Mann-Kendall statistics, if $t_{m}$ lies inside the range of $\pm r_{m}$, then the trend is not significant in the rainfall time series. For the Spearman test, if $t_{s}$ lies between $\pm r_{s}$ then the series does not have a trend. The direction of trends can be determined by using either technique [6].

For the long-range study (98 to 130 years) three stations, Colombo, Nuwara Eliya and Kandy showed a significant trend in rainfall data according to both the Mann-Kendal test and the Spearman test. Colombo has a positive or upward trend while the other two have negative or downward trends. Although four other stations, Anuradhapura, Galle, Badulla and Hambantota show somewhat significant trends compared to other stations, they are not significant at the $95 \%$ level.

For the short-range study (34 to 50 years) both tests indicate that there are significant negative trends in Kandy, Diyatalawa, Galle and Batticaloa. Note that only Kandy exhibits a significant negative trend for both time ranges. Although Colombo, Anuradhapura, Badulla, Trincomalee, Mannar and Jaffna show somewhat significant trends compared to other stations in both tests, they are not significant at the $95 \%$ confidence level. It should be noted that in the short-range trend analysis, 13 out of 15 stations displays negative Mann-Kendall statistics or in other 
words downward trends. Thus, the decreasing trends in rainfall records in the last half-century could be an indication of a temporal climatic change.

Table 2: Results of the trend test for long periods (98 to 130 years).

\begin{tabular}{|c|c|c|c|c|c|c|c|}
\hline \multirow[b]{2}{*}{ Station } & \multirow[b]{2}{*}{$\begin{array}{l}\text { Range } \\
\text { (Years) }\end{array}$} & \multicolumn{3}{|c|}{ Mann-Kendal Test } & \multicolumn{3}{|c|}{ Spearman Test } \\
\hline & & $\begin{array}{c}\text { Mann- } \\
\text { Kendal } \mathrm{t}_{\mathrm{m}}\end{array}$ & $\begin{array}{c}\text { Value at } \\
95 \% \text { level } \\
\pm r_{m}\end{array}$ & $\begin{array}{l}\text { Trend } \\
\text { exist }\end{array}$ & $\begin{array}{c}\text { Spearman } \\
\mathrm{t}_{\mathrm{s}}\end{array}$ & $\begin{array}{c}\text { Value at } 95 \% \\
\text { level } \\
\pm \mathrm{r}_{\mathrm{s}}\end{array}$ & $\begin{array}{l}\text { Trend } \\
\text { exist }\end{array}$ \\
\hline 1 Colombo & 130 & 0.17 & 0.12 & Yes & 3.26 & 1.98 & Yes \\
\hline 2 Nuwara Eliya & 130 & -0.32 & 0.12 & Yes & -6.13 & 1.98 & Yes \\
\hline 3 Rathnapura & 130 & -0.04 & 0.12 & No & -0.68 & 1.98 & No \\
\hline 4 Kandy & 129 & -0.20 & 0.12 & Yes & -3.46 & 1.98 & Yes \\
\hline 5 Anuradhapura & 129 & -0.10 & 0.12 & No & -1.81 & 1.98 & No \\
\hline 6 Diyatalawa & 98 & -0.06 & 0.13 & No & -0.69 & 1.98 & No \\
\hline 7 Galle & 125 & 0.08 & 0.12 & No & 1.31 & 1.98 & No \\
\hline 8 Badulla & 125 & -0.11 & 0.12 & No & -1.84 & 1.98 & No \\
\hline 9 Puttalam & 124 & 0.03 & 0.12 & No & 0.52 & 1.98 & No \\
\hline 10 Batticaloa & 125 & 0.06 & 0.12 & No & 0.85 & 1.98 & No \\
\hline 11 Kurunegala & 109 & 0.04 & 0.13 & No & 0.66 & 1.98 & No \\
\hline 12 Trincomalee & 118 & 0.02 & 0.12 & No & 0.26 & 1.98 & No \\
\hline 13 Mannar & 116 & 0.01 & 0.12 & No & 0.25 & 1.98 & No \\
\hline 14 Jaffna & 114 & 0.02 & 0.12 & No & 0.43 & 1.98 & No \\
\hline 15 Hambantota & 119 & 0.12 & 0.12 & No & 1.98 & 1.98 & No \\
\hline
\end{tabular}

The power of the two non-parametric rank based tests, the Mann-Kendall and the Spearman's test was analyzed using a Monte-Carlo simulation in the past [6]. Their work indicates that the two tests have similar power in detecting a trend. However, both tests only indicate a direction and not the magnitude. 
The straightforward technique that can be used to obtain the magnitude of a linear trend is the least-square regression method. The time series data records from all 15 stations were subjected to a linear regression and the results are summarized in table 4 for both ranges.

Table 3: Results of the trend test for short periods (36 to 50 years).

\begin{tabular}{|c|c|c|c|c|c|c|c|c|}
\hline & \multirow[b]{2}{*}{ Station } & \multirow[b]{2}{*}{$\begin{array}{l}\text { Range } \\
\text { (Years) }\end{array}$} & \multicolumn{3}{|c|}{ Mann-Kendal Test } & \multicolumn{3}{|c|}{ Spearman Test } \\
\hline & & & $\begin{array}{c}\text { Mann- } \\
\text { Kendal } t_{m}\end{array}$ & $\begin{array}{c}\text { Value at } \\
95 \% \text { level } \\
\pm \mathrm{r}_{\mathrm{m}}\end{array}$ & $\begin{array}{l}\text { Trend } \\
\text { exist }\end{array}$ & $\begin{array}{c}\text { Spearman } \\
\mathrm{t}_{\mathrm{s}}\end{array}$ & $\begin{array}{c}\text { Value at } \\
95 \% \text { level } \\
\pm \mathrm{r}_{\mathrm{s}}\end{array}$ & $\begin{array}{l}\text { Trend } \\
\text { exist }\end{array}$ \\
\hline 1 & Colombo & 50 & -0.10 & 0.19 & No & -0.96 & 2.021 & No \\
\hline 2 & Nuwara Eliya & 50 & -0.09 & 0.19 & No & -1.03 & 2.021 & No \\
\hline 3 & Rathnapura & 50 & -0.01 & 0.19 & No & -0.00 & 2.021 & No \\
\hline 4 & Kandy & 50 & -0.22 & 0.19 & Yes & -2.28 & 2.021 & Yes \\
\hline 5 & Anuradhapura & 50 & -0.15 & 0.19 & No & -1.55 & 2.021 & No \\
\hline 6 & Diyatalawa & 50 & -0.22 & 0.19 & Yes & -2.20 & 2.021 & Yes \\
\hline 7 & Galle & 45 & -0.24 & 0.20 & Yes & -2.51 & 2.021 & Yes \\
\hline 8 & Badulla & 45 & -0.12 & 0.20 & No & -1.05 & 2.021 & No \\
\hline 9 & Puttalam & 45 & -0.08 & 0.20 & No & -0.59 & 2.021 & No \\
\hline 10 & Batticaloa & 45 & -0.24 & 0.20 & Yes & -2.44 & 2.021 & Yes \\
\hline 11 & Kurunegala & 45 & -0.02 & 0.20 & No & -0.37 & 2.021 & No \\
\hline 12 & Trincomalee & 38 & -0.15 & 0.22 & No & -1.65 & 2.021 & No \\
\hline 13 & Mannar & 37 & 0.21 & 0.23 & No & 1.77 & 2.042 & No \\
\hline 14 & Jaffna & 36 & 0.12 & 0.23 & No & 1.11 & 2.042 & No \\
\hline 15 & Hambantota & 39 & -0.11 & 0.22 & No & -0.76 & 2.021 & No \\
\hline
\end{tabular}

The results show the confirmation of the Mann-Kendall and the Spearmann's tests by the linear trend analysis. However, the regression analysis also indicates a significant trend at Badulla. We attribute the failure of detecting a significant trend at a 95\% confidence level at Badulla by the Mann-Kendall and the Spearmann's test to the higher inter-annual variability of rainfall at this location. 
K.H.W.I. Jayawardene et. al. / Sri Lankan Journal of Physics, Vol.6 (2005) 7-17

Table 4: Results obtained from a linear fit by regression analysis.

\begin{tabular}{llcccccc}
\hline & & \multicolumn{3}{c}{ Long Range } & & Short Range & \\
\cline { 3 - 8 } & \multicolumn{1}{c}{ Station } & Slope & $\begin{array}{c}\text { Significance } \\
\text { of t }\end{array}$ & $\begin{array}{c}\text { Trend } \\
\text { Exist }\end{array}$ & Slope & $\begin{array}{c}\text { Significance } \\
\text { of t }\end{array}$ & $\begin{array}{c}\text { Trend } \\
\text { Exist }\end{array}$ \\
& & & & & 0.15 & No \\
\hline 1 & Colombo & 3.15 & 0.01 & Yes & -6.36 & 0.09 & No \\
2 & Nuwara Eliya & -4.87 & 0.00 & Yes & -5.31 & No \\
3 & Rathnapura & -0.76 & 0.50 & No & -0.59 & 0.89 & No \\
4 & Kandy & -2.88 & 0.00 & Yes & -6.75 & 0.02 & Yes \\
5 & Anuradhapura & -1.19 & 0.10 & No & -5.68 & 0.08 & No \\
6 & Diyatalawa & -0.83 & 0.41 & No & -5.30 & 0.04 & Yes \\
7 & Galle & 0.82 & 0.42 & No & -10.45 & 0.01 & Yes \\
8 & Badulla & -2.22 & 0.02 & Yes & -3.03 & 0.39 & No \\
9 & Puttalam & 0.29 & 0.67 & No & -1.60 & 0.66 & No \\
10 & Batticaloa & 0.63 & 0.50 & No & -11.16 & 0.03 & Yes \\
11 & Kurunegala & 0.11 & 0.99 & No & -0.92 & 0.82 & No \\
12 & Trincomalee & 0.65 & 0.51 & No & -7.48 & 0.23 & No \\
13 & Mannar & 0.05 & 0.94 & No & 5.82 & 0.15 & No \\
14 & Jaffna & 0.17 & 0.87 & No & 4.95 & 0.34 & No \\
15 & Hambantota & 1.09 & 0.12 & No & -3.41 & 0.38 & No \\
\hline
\end{tabular}

The regression results show that in the long run, the largest decrease in rainfall amounts of $4.87 \mathrm{~mm} /$ year is at Nuwara Eliya. On the other hand, Colombo shows a significant increasing trend of $3.15 \mathrm{~mm} /$ year. According to the results, there were no significant monotonic trends in most of the stations in Sri Lanka in the long-term rainfall records. Thus, in general, it can be stated that Sri Lankan rainfall has been quite stable over the last century.

For the more recent period of the past 50 years, the computed trend values are higher, and most of the trends are negative. The downward trend at Kandy is steeper in recent decades (during the last half century) compared to the long term (last century) variation. The largest downward trend of $11.16 \mathrm{~mm} /$ year was observed at Batticaloa. Since there is no regional connection between the four stations that passed through the statistical test at $95 \%$ confidence 
level and 13 out of 15 stations showed decreasing trend, there may possibly be an impact due to deforestation, urbanization etc, seen by the rainfall time series during the recent period.

Only a few comprehensive studies have been conducted in Sri Lanka on the trends of rainfall depth over long periods. Domroes and Schaefer [7] has carried out a similar study for annual rainfall over two time periods $(1895$ - 1996 and 1960 - 1996) for 13 out of 15 stations considered in this study. They observed statistically significant decreases in rainfall in Anuradhapura, Kandy and Nuwara Eliya over the period 1895-1996 and Batticaloa with a significant decrease in precipitation over the shorter period. Malmgren et. al. [8] has carried out an analysis to study long term seasonal precipitation trends for the same 15 stations used in this work (time period 1870 - 2000). Their results show statistically significant increasing trends at Colombo, Hambantota and Puttalam and decreasing trends at Kandy and Nuwara Eliya for the Southwest monsoons. No significant trends have been observed for the Northeast monsoons. Only Nuwara Eliya shows decreasing trends for the first inter monsoon as well as for the second inter monsoon.

A recent study done by Madduma Bandara et. al. [9] has indicated a significant decline in rainfall at Nuwara Eliya and several other stations on the western slopes of the highlands over the last century. They have identified reduction of the Southwest monsoon rainfall as the cause for the decline in overall rainfall on the western slopes. No significant trends have been observed for the stations in the eastern side such as Badulla.

\section{CONCLUSIONS}

This study focused on analyzing the trends of rainfall recorded in 15 meteorological stations over the last century.

The significance of trends was evaluated with the Mann-Kendal rank statistic, the Spearman rank statistic and the regression slope method. The trends were tested for two periods, a long term period (1869 onwards) and a short term (1949 onwards). A long-term increasing trend at the $95 \%$ confidence level was observed at Colombo with a rate of $3.15 \mathrm{~mm} /$ year. Decreasing long-term trends were found at two locations, Nuwara Eliya at a rate of $4.87 \mathrm{~mm} / \mathrm{year}$ and 
Kandy at a rate of $2.88 \mathrm{~mm} /$ year. No coherent increase or decrease in trends was observed for stations in the wet or the dry zones during the last century. However, a recent study [9] has indicated a significant decline in rainfall in several stations (in close proximity) on the western slopes of the highlands. The principal cause for this was identified as the reduction of the Southwest monsoon rainfall.

For the short term study, significant decreasing trends at the $95 \%$ confidence level were observed at four stations Kandy, Diyatalawa, Galle, and Batticaloa at rates of 6.75, 5.30, 10.45 and $11.16 \mathrm{~mm} /$ year respectively. Since 13 out of the 15 stations showed decreasing trends, a possible sign of temporal change in Sri Lankan rainfall over the past half century may be apparent in the rainfall records.

The results observed for Kandy and Nuwara Eliya in this work are confirmed by the two studies discussed earlier [7, 8]. The study conducted on the seasonal rainfall [8] confirms the results for Colombo where as the study conducted on the annual rainfall [7] confirms the results for Batticaloa. A closer inspection shows that the trend analyses are somewhat sensitive to the time periods considered. Thus, we attribute the differences observed to the differences in the time periods considered in each of the three studies.

\section{ACKNOWLEDGEMENTS}

Financial assistance by IPPS, Uppsala University, Sweden (research grant number SRI:01/1), and the National Science Foundation, Sri Lanka (grant number RG/2000/P/01) are acknowledged.

\section{REFERENCES}

1. Domroes, M., E. Ranatunge, A Statistical approach towards a regionalization of daily rainfall in Sri Lanka, I. J. of Climatology, 13 (1993) 741-754.

2. Yoshino, M. M., R. Suppiah, Climatological Notes, Climatic records of monsoon Asia, Institute of geosciences, University of Tskuba (1982).

3. Abrol, Y. P., S. Gadgil, G.B. Pant, Climate variability and agriculture, Narosha publishing house, New Delhi, India (1996). 
4. Mitchell, J. M., B. Dzerdeevskii, H. Flohn, W.L. Hfmeyr, H.H. Lamb, K.N. Rao, N. Wallen, C. C., Annexes, Climate change, WMO, Tech. Note, 79 (1969) 33-79.

5. Perera, H.K.W.I., Exploring the spatial and temporal variations of rainfall in Sri Lanka, M.Phil Thesis, University of Colombo (2003).

6. Pilon, Y. S., G. Cavadias, Power of the Mann-Kendall and Spearman's rho tests for detecting monotonic trends in hydrological series, Journal of Hydrology, 259 (1-4), (2002) 254-271.

7. Domroes, M., D. Schaefer, Trends of recent temperature and rainfall changes in Sri Lanka, Proceedings of the International Conference on Climate Change and Variability, Tokyo Metropolitan University (2000) 197-204.

8. Malmgren B.A., R. Hulugalla, Y. Hayashi, T. Mikami, Precipitation trends in Sri Lanka since the 1870s and relation to El Nino-southern Oscillation, International Journal of Climatology, $\underline{23}$ (2003) 1235-1252

9. Madduma Bandara C.M., P. Wickremagamage, Climate change and its impact on upper watersheds of the hill country of Sri Lanka, Proc. Int. Conf. on Sustainable Water Resources Management in Changing Environment of the Monsoon Region, Colombo (2004) 94-109 